\title{
Influence of basic fibroblast growth factor on the growth of HeLa cells and the expression of angiogenin
}

\author{
JIANLI YANG, JI WANG, JIA ZHAO, DAN ZUO, XINGRONG LI and LI WANG \\ Institute of Genetics and Cytology, School of Life Science, Northeast Normal University, Changchun, P.R. China
}

Received September 23, 2008; Accepted November 18, 2008

DOI: $10.3892 /$ or_00000308

\begin{abstract}
Basic fibroblast growth factor (bFGF) is closely involved in angiogenesis and tumor growth of various cancers, but its role in cervical cancer remains to be defined. We investigated the effects of bFGF on HeLa cell growth and studied its influence on the expression of angiogenin. We transfected the bFGF gene in the sense and antisense orientation into HeLa cells, and obtained stable bFGF underexpressing and overexpressing transfectants. In our experiments, we demonstrated that inhibition of bFGF gene and protein expression in the bFGF antisense transfectants induced increased protein expression of angiogenin. In contrast, in the bFGF sense transfectants the expression of angiogenin decreased. Delivery of recombinant angiogenin into transfected and control cells led to increased proliferation in the bFGF antisense transfectants and the control cells. However, the cell proliferation had no change in the bFGF sense transfectants. In conclusion, we demonstrated that besides its angiogenic activity, bFGF and angiogenin also directly contribute to HeLa cell proliferation. Furthermore, endogenous bFGF affects the expression of angiogenin in HeLa cells. These findings suggest that inhibition of bFGF alone is not a promising strategy to inhibit angiogenesis.
\end{abstract}

\section{Introduction}

Cancer of the uterine cervix is the second most common cancer among women in the world (1), and the most common gynecological malignancy in P.R. China. Angiogenesis stimulates tumor growth, invasion and metastasis, and therefore is a crucial step in tumorigenesis. Further, evidence of increased neovascularization has been shown to be a negative prognostic indicator in many solid tumors, including cervical cancer (2). Several growth factors may be involved in the angiogenic process, including angiogenin and basic fibroblast growth factor (bFGF).

Correspondence to: Dr Li Wang, Institute of Genetics and Cytology, School of Life Science, Northeast Normal University, Changchun, P.R. China

E-mail: wangli@nenu.edu.cn

Key words: HeLa cell, basic fibroblast growth factor, angiogenin, transfection
Angiogenin is a $14-\mathrm{kDa}$ angiogenic protein originally isolated from the conditioned medium of HT-29 human colon adenocarcinoma cells (3). Angiogenin has been shown to play a role in tumor angiogenesis (4). Its expression is upregulated in many types of cancers (5-10). Angiogenin undergoes nuclear translocation in endothelial cells, which has been shown to be necessary for angiogenesis (11-13). Tsuji et al have shown that nuclear translocation of angiogenin occurred in HeLa cells regardless of the cell confluence status, and that angiogenin stimulated rRNA synthesis in HeLa nuclei (14). Many studies have focused on how angiogenin induced tumor angiogenesis and how its angiogenic activity can be disrupted. Little, however, is known about its expression and function during HeLa cell growth.

Basic fibroblast growth factor (bFGF), a member of a group of heparin-binding multifunctional polypeptides, is one of the most potent angiogenic factors $(15,16)$. It is also involved in proliferation and differentiation of a variety of normal and malignant cells and tissues $(17,18)$. Many malignant tumors showed an increase in bFGF expression (19-22). Sliutz et al have demonstrated that serum basic fibroblast growth factor of cervical cancer patients increases (23).

The role of individual angiogenic growth factors in the formation of new blood vessels and in the progression of tumor growth has been extensively investigated. The expression of angiogenin and bFGF is especially associated with a poor prognosis. Nevertheless, little is known about how these factors coordinately regulate tumor angiogenesis and how they react on the targeted inhibition of a single factor. Kishimoto et al have observed that angiogenin antisense HeLa transfectants and tumors in athymic mice actually expressed a higher amount of bFGF than the control cells and tumors in athymic mice (24). Song et al demonstrated that the angiogenin sense transfectants actually expressed a lower amount of bFGF, and the angiogenin antisense transfectants expressed a higher amount of bFGF than A375 cells (25). To further understand the biological role of angiogenin and bFGF, we investigated the influence of bFGF on angiogenin gene expression and angiogenin secretion in HeLa cell lines.

\section{Materials and methods}

Cell line. A HeLa cell line was acquired from the Institute of Biochemistry and Cell Biology, Chinese Academy of Sciences 


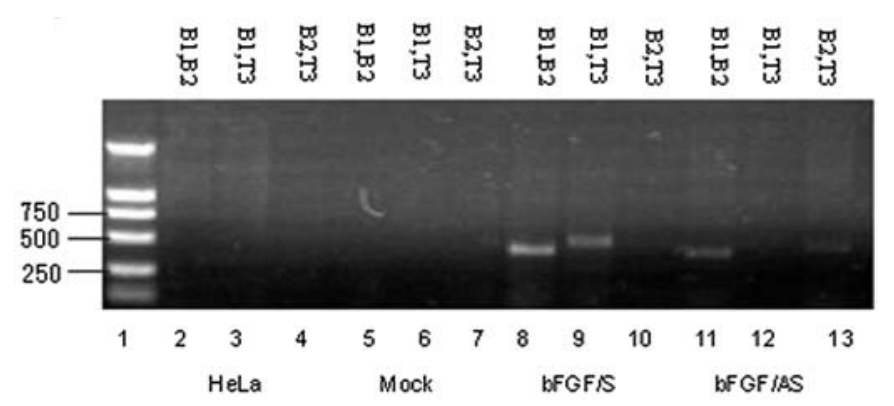

Figure 1. Polymerase chain reaction (PCR) identification of transfection from the genomic DNA. After 3 weeks of transfection, the cloned transfectants were examined by PCR amplification to confirm the integration of transfected bFGF gene into the chromosomes. HeLa cells and vectortransfected cells (Mock) had no PCR products amplified by either a set of $\mathrm{B} 1$ and $\mathrm{B} 2$ primers or $\mathrm{B} 1$ and $\mathrm{T} 3$ primers or a set of $\mathrm{B} 2$ and $\mathrm{T} 3$ primers (lanes 2, 3, 4, 5, 6, and 7); bFGF sense transfectants (bFGF/S) had 575 bp products amplified by B1 and T3 primers (lane 9), and no products amplified by B2 and T3 primers (lane 10). It indicated that the transfected bFGF gene had integrated into genomic DNA of HeLa cells in the sense orientation; bFGF antisense transfectants (bFGF/AS) had 568 bp products amplified by B2 and T3 primers (lane 13), and no products amplified by B1 and $\mathrm{T} 3$ primers (lane 12). It indicated that the transfected bFGF gene had integrated into genomic DNA of HeLa cells in the antisense orientation. BFGF sense transfectants and bFGF antisense transfectants could be amplified by B1 and B2 primers, and the PCR products were 489 bp (lanes 8 and 11).

in Shanghai. HeLa cells were cultured in Dulbecco's modifed Eagle's medium (DMEM) supplemented with $10 \%$ (v/v) heat-inactivated fetal bovine serum (FBS) at $37^{\circ} \mathrm{C}$ in a humidified atmosphere containing $5 \% \mathrm{CO}_{2}$.

Stable transfection of HeLa cells. HeLa cells were transfected with pCI-bFGF $( \pm$ ) plasmids (we constructed the plasmids and sequenced DNA) or with pCI-neo vector alone by using the electroporation method. Briefly, cultured cells were resuspended at $1 \times 10^{7} \mathrm{cell} / \mathrm{ml}$. Then, $300 \mu 1$ of cell suspension was mixed with $60 \mu \mathrm{g}$ of liberalized expression plasmid DNA on ice and electroporated using a Bio-Rad gene pulser Xcell ${ }^{\mathrm{TM}}$ Electroporation System (Bio-Rad Laboratories Inc., Hercules, CA, USA). The pulse for transfection was $150 \mathrm{~V}$. After $48 \mathrm{~h}$, the media were replaced with fresh selective media containing $1 \mathrm{mg} / \mathrm{ml} \mathrm{G} 418$ (Invitrogen Corporation, Grand Island, NY, USA).

Polymerase chain reaction analysis of transfected genes in cloned cells. After 3 weeks of selection, we analyzed the transfected cDNAs in cloned cells. The cells from each clone were submitted to the genomic DNA polymerase chain reaction (PCR) analysis to confirm the integration of the transfected gene into the chromosomes. PCR primers were B1, bFGF forward sequence (5'-TCTGAATTCATGGCA GCCGGGAGCATCAC-3'); B2, bFGF reverse sequence (5'-TCTGGTCGAAAAATCAGCTCTTAGCAGAC-3'); and T3, from the pCI vector (5'-ATCATGTCTGCTCGAAGC ATTAAC-3'). Genomic DNA was extracted from confluent cells as described (26). The PCR conditions consisted of temperature of $94^{\circ} \mathrm{C}$ for $5 \mathrm{~min}$, followed by 30 cycles of amplification at $94^{\circ} \mathrm{C}$ for $30 \mathrm{sec}, 58^{\circ} \mathrm{C}$ for $30 \mathrm{sec}$ and $72^{\circ} \mathrm{C}$ for $30 \mathrm{sec}$.
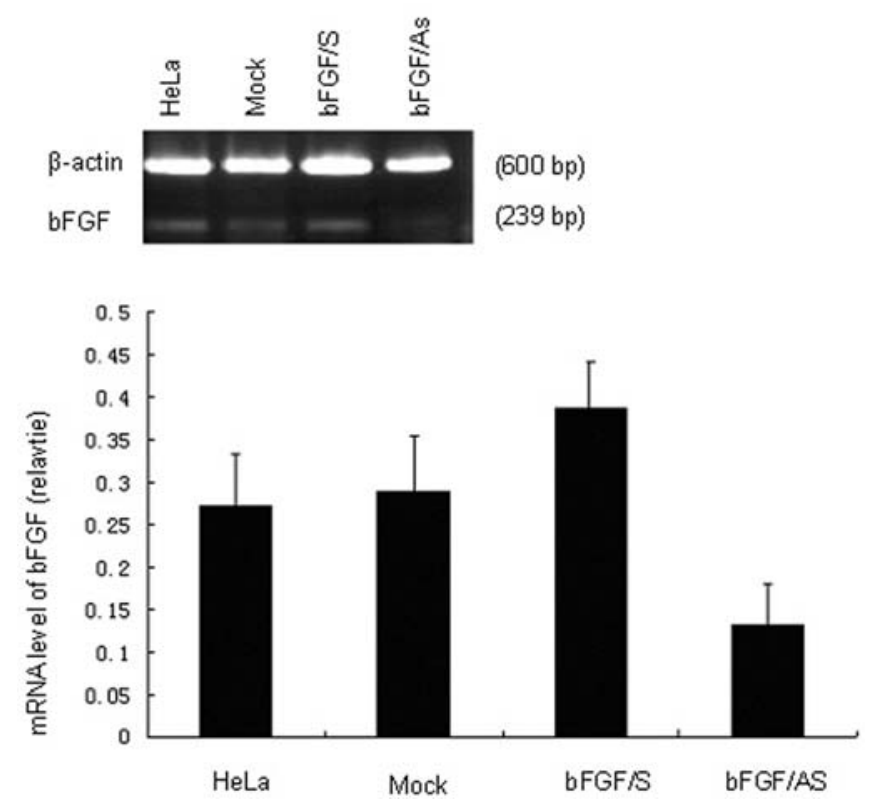

Figure 2. Expression of bFGF mRNA in bFGF transfected and control cells was measured by RT-PCR. Total RNA was isolated from cultured cells and RT-PCR was performed as described in Materials and methods. B-actin mRNA expression was as an internal control. The ratio of the amount of bFGF mRNA to that of $\beta$-actin mRNA was evaluated by densitometric analysis. The histogram shows quantitative representations of the bFGF mRNA expression levels in cells from 4 independent experiments (using cells from different preparations). Each value represents the mean \pm SD.

Semi-quantitative RT-PCR. Semi-quantitative RT-PCR was used to determine the relative changes of mRNA transcripts in bFGF transfectants. Total RNA was isolated from cultured cells using TRIzol (Invitrogen Corporation, Grand Island, NY, USA). First-strand cDNA was synthesized from $1 \mu \mathrm{g}$ of total RNA using an RT kit (Promega Corporation, Madison, WI, USA). The following primer sequences were used: 5'-ATG GCAGCCGGGAGCATCACC-3' (sense), 5'-CACACACTC CTTTGATAGACACAA-3' (antisense) for bFGF (25); 5'-CA TCATGAGGAGACGGGG-3' (sense), 5'-TCCAAGTGG ACAGGTAAGCC-3' (antisense) for angiogenin; and 5'-ACA CTGTGCCCATCTACG-3' (sense), 5'-CTCGTCATACTC CTGCTTG-3' (antisense) for $\beta$-actin as an internal loading control and for normalization of the PCRs.

Cell cycle and proliferation analyses. For cell cycle analysis, cells were harvested by trypsinization, fixed overnight at $4^{\circ} \mathrm{C}$ in $70 \%$ ethanol and incubated for $30 \mathrm{~min}$ at room temperature in PBS with $50 \mu \mathrm{g} / \mathrm{ml}$ propidium iodide and $100 \mathrm{U} / \mathrm{ml} \mathrm{ribo-}$ nuclease A. Fluorescence intensity was determined in Beckman EPICS XL ADC flow cytometer, and the proportion of cells in different phases of the cycle was estimated using Multi Cycle AV for Windows Analyses Software.

Cell proliferation was quantified by the MTT (thiazol blue tetrazolium bromide) assay. Briefly, transfected cells $\left(7.0 \times 10^{3}\right)$ were seeded into 96 -well plates at a density. Triplicate wells were used for each treatment. After $48 \mathrm{~h}$ of incubation, a $10 \mu 1 \mathrm{MTT}$ solution $(5 \mathrm{mg} / \mathrm{ml}$ in PBS) was added to each well. Wells containing only medium and MTT were used as controls for each plate. The tetrazolium/ formazan reaction was allowed to proceed for $4 \mathrm{~h}$ at $37^{\circ} \mathrm{C}$, and 
then $100 \mu 1$ of the solubilization buffer (10\% sodium dodecyl sulfate in $0.1 \% \mathrm{HCl}$ ) was added to all the wells to stop the reaction. The absorbance was determined using a 96-well multiscanner autoreader at $540 \mathrm{~nm}$.

Immunofluorescence. The expression of angiogenin in transfected cells was analyzed by immunofluorescence staining. Cells were washed with PBS, fixed with cold methanol and washed again with PBS containing $5 \%$ bovine serum albumin (BSA), then incubated with anti-angiogenin polyclonal antibodies (R\&D Systems, Minneapolis, MN, USA) at 1:100 dilution for $1 \mathrm{~h}$ at $37^{\circ} \mathrm{C}$. After washing with PBS, the cells were incubated with fluorescein isothiocyanate-conjugated rabbit anti-goat IgG (Beijing Zhongshan Golden Bridge Biotechnology Co. Ltd, Beijing, P.R. China) at 1:100 dilution for $1 \mathrm{~h}$ at room temperature, then washed and observed under a fluorescence microscope (Nikon Eclipse, Yokahama, Japan).

Western blot analysis. The cells were harvested and lysed with lysis buffer [20 mM Tris- $\mathrm{HCl}, \mathrm{pH} 7.5,5 \mathrm{mM}$ ethylenediaminetetraacetic acid, $5 \mathrm{mM}$ ethyleneglycol-bis-(ß-amino ethyl ether)- $\mathrm{N}, \mathrm{N}, \mathrm{N}^{\prime}, \mathrm{N}^{\prime}$,-tetraacetic acid, $50 \mathrm{mM} \mathrm{NaF}, 1 \mathrm{mM}$ $\mathrm{NH}_{4} \mathrm{VO}_{4}, 30 \mathrm{mM} \mathrm{Na} \mathrm{P}_{2} \mathrm{O}_{7}, 50 \mathrm{mM} \mathrm{NaCl}, 1 \%$ Triton X-100 and $1 \mathrm{mM}$ phenylmethylsulfonyl fluoride]. Equal amounts of total proteins were separated by $15 \%$ sodium dodecyl sulfate polyacrylamide gel electrophoresis and electrophoretically transferred to nitrocellulose membrane. The membrane was then blocked overnight at $4{ }^{\circ} \mathrm{C}$ with $5 \%$ non-fat dried milk in TBST (10 mM Tris pH 7.5, $150 \mathrm{mM} \mathrm{NaCl)} \mathrm{containing} 0.1 \%$ Tween-20. Afterwards, the membrane was incubated with anti-bFGF polyclonal antibodies (R\&D Systems), antiangiogenin $\mathrm{mAb}$ polyclonal antibodies (R\&D Systems) and anti-actin mAb AC-15 Sigma (Sigma-Aldrich, St. Louis, MO, USA) for $1 \mathrm{~h}$ at $37^{\circ} \mathrm{C}$. After washing with TBST, the membrane was incubated with HRP-conjugated anti-mouse IgG (Beijing Zhongshan Golden Bridge Biotechnology Co. Ltd.) for $1 \mathrm{~h}$ at $37^{\circ} \mathrm{C}$. The results were revealed by using Pierce Biotechnology SuperSignal West pico chemiluminescent substrate pierce (Rockford, IL, USA).

ELISA detection of angiogenin. The angiogenin secretion levels were detected by enzyme-linked immunosorbent assay (ELISA) as described (27). Briefly, ELISA plates were coated with $1 \mu \mathrm{g}$ 26-2F/well (26-2F was provided by Dr Guo-fu Hu, Harvard Medical School) and blocked with $5 \mathrm{mg} / \mathrm{ml}$ bovine serum albumin in PBS. Samples were added in triplicates $(100 \mu 1)$, and the plates were incubated at $4^{\circ} \mathrm{C}$ overnight, washed with PBS 5 times and incubated with $100 \mu \mathrm{l} /$ well anti-angiogenin polyclonal antibody (R\&D Systems) at $37^{\circ} \mathrm{C}$ for $1 \mathrm{~h}$. After washing 4 times with PBS, horseradish peroxidase (HRP)-conjugated anti-rabbit IgG (Beijing Zhongshan Golden Bridge Biotechnology Co. Ltd.) was added to each well, and the plates were incubated for $1 \mathrm{~h}$ at $37^{\circ} \mathrm{C}$. The plates were washed 4 times with PBS, and then $50 \mu 1$ of substrate $3,3^{\prime}, 5,5^{\prime}$-tetramethylbenzidine TMB (3,3',5,5'-Tetramethylbenzidine) solution was added. After $30 \mathrm{~min}$ of incubation at room temperature, the reaction was stopped by adding $50 \mu \mathrm{l}$ of $2 \mathrm{mmol} / \mathrm{ml} \mathrm{H}_{2} \mathrm{SO}_{4}$, and the absorbance of each well was read by a 96-well multiscanner autoreader (Multiskan Ascent, Labsystems, Finland) at $450 \mathrm{~nm}$.
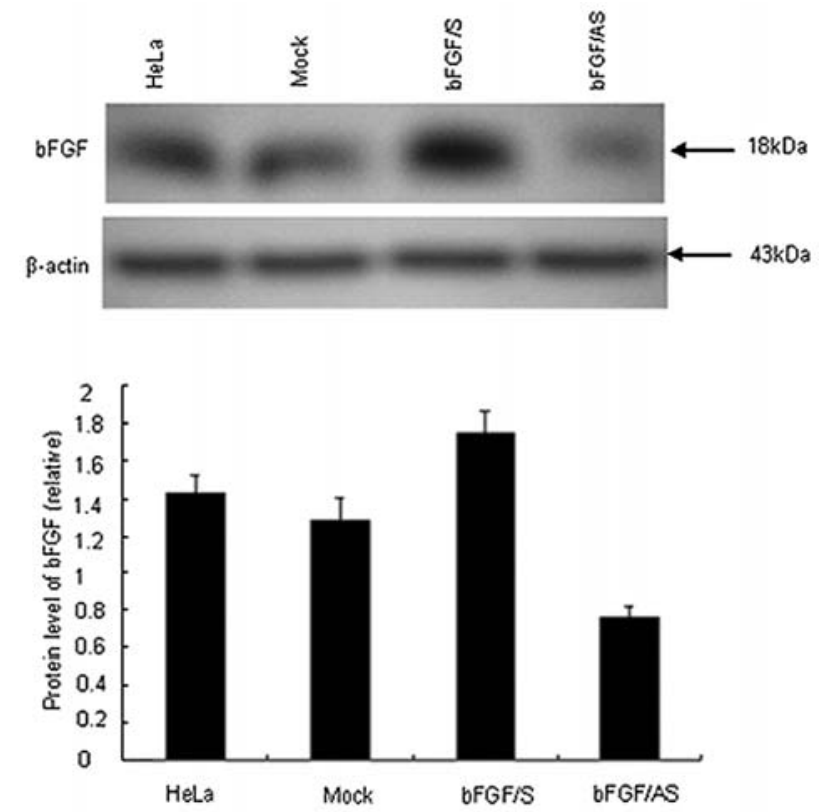

Figure 3. Western blot analysis of bFGF protein in bFGF transfected and control cells. Cells $\left(3 \times 10^{6}\right)$ were harvested and lysed with lysis buffer. Then the extracts of cells were subjected to sodium dodecyl sulfate polyacrylamide gel electrophoresis with subsequent Western blot analysis using anti-bFGF antibody and anti- $\beta$-actin antibody, then with chemiluminescent detection on X-ray film. B-actin was used as the loading control. The bars show quantitative representations of the expression levels of bFGF obtained from densitometric analysis (similar results were obtained with two additional and different cell reparations).

A standard curve of recombinant human angiogenin at concentrations ranging from 25 to $800 \mathrm{pg} /$ well was performed each time on every plate.

Statistics. Experimental results are expressed as means \pm SD of at least three independent experiments. Student's t-test was used for statistical analysis. The threshold of significance was set at $\mathrm{P}<0.05$.

\section{Results}

Polymerase chain reaction identification of transfection. To study the biological function of bFGF, we transfected the bFGF gene in the sense and antisense orientations into HeLa cells. The bFGF sense transfectants were confirmed by the PCR products that were amplified with a set of $\mathrm{B} 1$ and $\mathrm{T} 3$ primers, and the product size was $575 \mathrm{bp}$. Alternatively, the PCR products that were amplified with a set of B2 and T3 primers for bFGF antisense transfectants were 568 bp (Fig. 1). BFGF sense transfectants and bFGF antisense transfectants could be amplified by B1 and B2 primers, and the PCR products were $489 \mathrm{bp}$. These results indicated that the transfected bFGF gene had integrated into the genomic DNA of HeLa cells.

Expression of bFGF in sense and antisense transfectants. We examined the bFGF expression level in the transfectants by RT-PCR (Fig. 2) and Western blotting (Fig. 3). Figs. 2 and 3 show that the bFGF expression level was reduced in the bFGF antisense transfectants, whereas it increased in the 

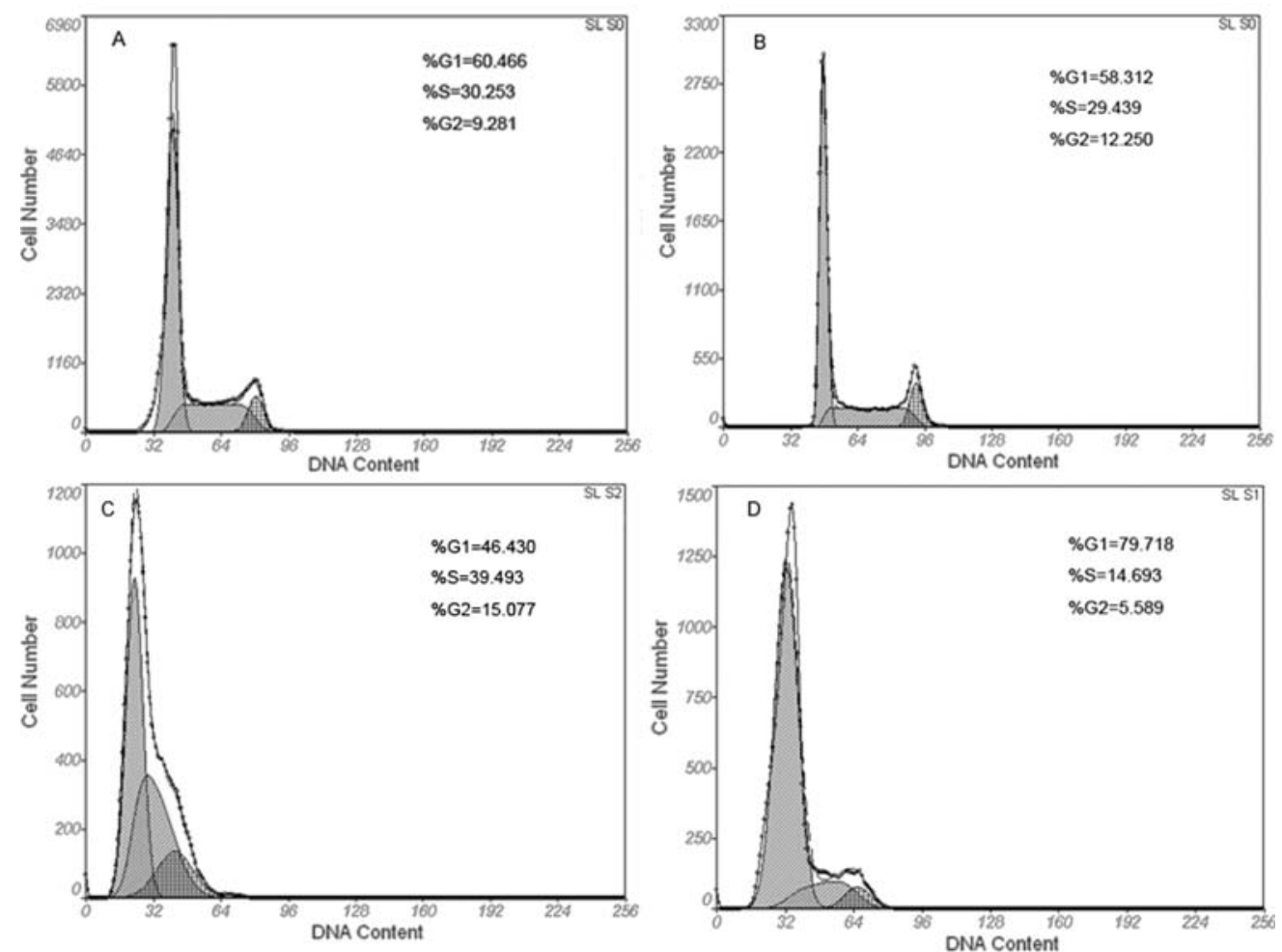

Figure 4. The effect of bFGF gene transfection on HeLa cell growth. The cell cycle analysis (A, B, D and E): 4x105 cells were cultured in 6-wells cell culture plates for $48 \mathrm{~h}$. Cells were harvested, DNA stained with propidium iodide, and the cell cycle was analyzed by flow cytometry. The results were expressed as DNA content in the different phases of the cell cycle. The number of bFGF sense transfected cells (C) in the S and G2 phases increased compared with the HeLa cells (A) and vector-transfected cells (B). Whereas the number of bFGF antisense transfected cells (D) in the S and G2 phases decreased compared with the control cells.

bFGF sense transfectants at both the mRNA and the protein levels. These results demonstrated that the stable bFGF underexpressing transfectants and overexpressing transfectants were obtained.

Effect of bFGF sense and antisense gene transfer on cell proliferation. To determine whether endogenous bFGF also influences the HeLa cell proliferation, we performed the flow cytometry assay. As shown in Fig. 4, the number of bFGF sense transfected cells in the S phase increased $27 \%$ compared with the control cells, and the number of cells in G2 phase also increased. Conversely, the number of bFGF antisense transfected cells in the $\mathrm{S}$ phase decreased $48 \%$ compared with the control cells and the percentage of cells in G2 phase also decreased.

bFGF sense and antisense gene transfer affects angiogenin expression. Since HeLa cells secrete many angiogenic factors, cell growth could not be attributed solely to bFGF. Herein, we examined the expression of angiogenin, which is another mediator of the proliferation of HeLa, in the bFGF transfected cells. RT-PCR analysis was performed to determine the level of angiogenin mRNA expression. Fig. 5 shows that the sense and antisense transfectants expressed identical amounts of angiogenin as the control cells. Cellular and secreted angiogenin were determined by the Western blotting assay and ELISA, respectively (Figs. 6 and 7). Densitometric analysis showed that the amount of angiogenin was higher in the bFGF antisense transfectants than that in

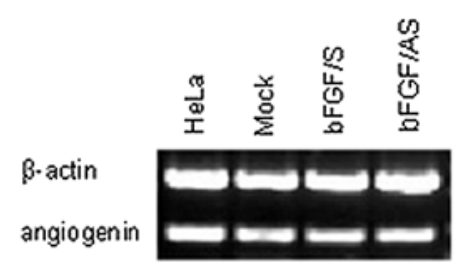

(œ00p)
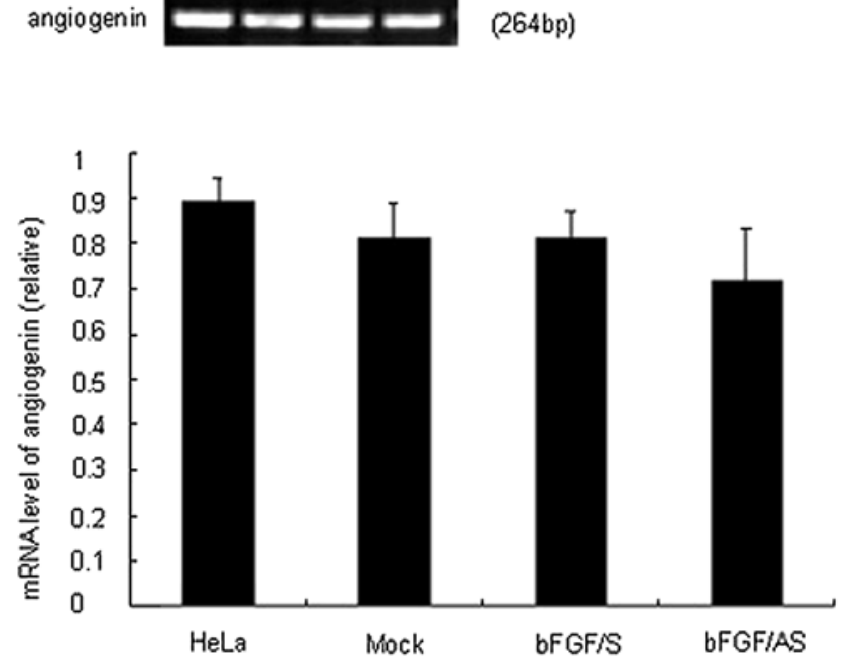

Figure 5. Expression of angiogenin mRNA in bFGF transfected and control cells was measured by RT-PCR. Total RNA was isolated from cultured cells and RT-PCR was performed as described in Materials and methods. B-actin mRNA expression was as an internal control. The ratio of the amount of angiogenin mRNA to that of B-actin mRNA was evaluated by densitometric analysis. The histogram shows quantitative representations of the angiogenin mRNA expression levels in cells from four independent experiments (using cells from different preparations). Each value represents the mean \pm SD. 

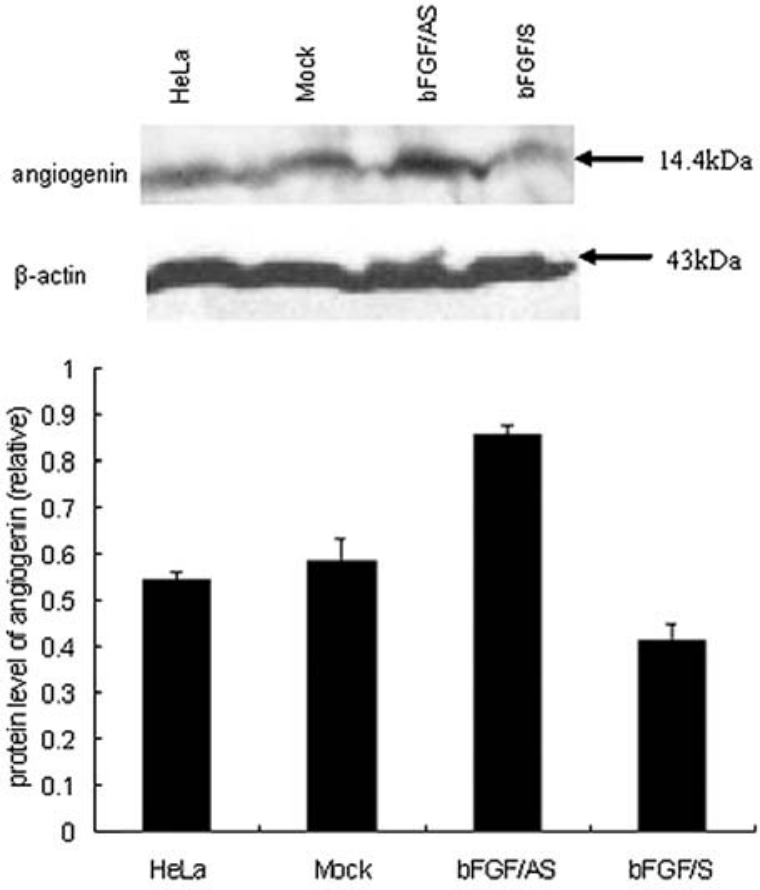

Figure 6. Western blot analysis of cellular angiogenin in bFGF transfected and control cells. Cells $\left(3 \times 10^{6}\right)$ were harvested and lysed with lysis buffer. Then the extracts of cells were subjected to sodium dodecyl sulfate polyacrylamide gel electrophoresis with subsequent Western blot analysis using anti-angiogenin antibody and anti- $\beta$-actin antibody, then with chemiluminescent detection on X-ray film. ß-actin was used as the loading control. The bars show quantitative representations of the expression levels of angiogenin obtained from densitometric analysis (similar results were obtained with two additional and different cell preparations).

the control cells. The amount of angiogenin, however, was lower in the bFGF sense transfectants. The secretion levels of angiogenin in culture supernatants were determined by ELISA, which provided a quantitative measurement. Fig. 7 shows that secreted angiogenins were higher in the bFGF antisense transfectants and lower in the bFGF sense transfectants, which was consistent with Western blotting. The immunofluorescence assay showed a reduction of immunoreactivity in the bFGF sense transfectants and an increased immunoreactivity in the bFGF antisense transfectants (Fig. 8). No difference was observed between the HeLa parent cells and the vector-transfected control cells.

Effect of exogenous angiogenin on cell proliferation of stable bFGF sense and antisense transfectants. To further confirm if angiogenin could effect cell proliferation in bFGF transfectants, we added exogenous angiogenin to bFGF sense and antisense transfected cells. As shown in Fig. 9, exogenous angiogenin reversed the effects of bFGF antisense plasmid. Data show that the angiogenin promoted cell proliferation in HeLa cells and vector-transfected control cells, but it had no effect on the bFGF sense transfectants.

\section{Discussion}

As a cell factor, it can stimulate cell growth, wound healing, tissue repair, hematopoiesis and may play an important role in tumor growth. Our experiments have shown that endogenous bFGF expression affects HeLa cell proliferation. The

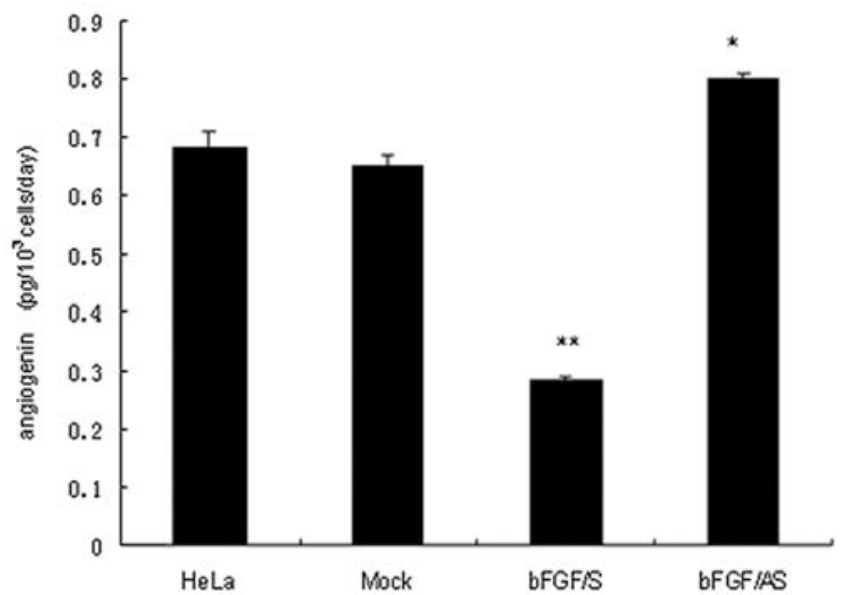

Figure 7. The amount of secreted angiogenin in bFGF transfected cells was determined by ELISA. The cells were seeded in a $100-\mathrm{mm}$ plate at a certain density and cultured in Dulbcco's modifed Eagle's medium supplemented with $10 \%$ fetal bovine serum at $37^{\circ} \mathrm{C}$ under humidified $5 \% \mathrm{CO}_{2}$ for $24 \mathrm{~h}$. The cells were washed 3 times with pre-warmed $\left(37^{\circ} \mathrm{C}\right)$ serum-free medium and serum-starved for $48 \mathrm{~h}$. Then the culture media were collected and centrifuged to remove particles. The levels of angiogenin were determined by ELISA and normalized to cell numbers. The data shown are means \pm SD of 4 independent experiments $\left({ }^{*} \mathrm{P}<0.002\right.$ compared with $\mathrm{HeLa},{ }^{* *} \mathrm{P}<0.001$ compared with HeLa).

cell proliferation of bFGF antisense transfectants decreased. However, the cell proliferation of bFGF sense transfectants increased (Fig. 4). It indicated that endogenous bFGF was important in HeLa cell proliferation.

We have examined the effects of bFGF on the expression of angiogenin in HeLa cells. Interestingly, we found that bFGF antisense transfected cells actually expressed a higher amount of angiogenin protein, and the bFGF sense transfectants expressed a lower amount of angiogenin protein (Figs. 6-8). This result is similar to that of Kuhn et al $(28,29)$, who reported that inhibition of bFGF gene expression caused upregulation of VEGF in H460 and H1299 cells. BFGF had no effect on the expression of angiogenin mRNA. These results demonstrated that bFGF affected the expression of angiogenin at the post-transcription level. Kishimoto et al reported that the expression of bFGF increased in angiogenin antisense transfected HeLa cells (24). Song et al found that the angiogenin sense transfected A375 actually expressed a lower amount of bFGF, and the angiogenin antisense transfectants expressed a higher amount of bFGF than the control cells (25). It seems that bFGF and angiogenin could interact, although the mechanism is still unclear.

It is worth noting that though the cell proliferation decreased in bFGF antisense transfected cells, the expression level of angiogenin increased (Figs. 6-8). Other researchers found that the expression of VEGF increased after the growth of tumor cells was inhibited. The inhibition of tumor cell growth by conventional forms of therapy such as irradiation or low dose chemotherapy led to an increase of VEGF expression $(30,31)$. Gene expression studies comparing dense and sparse growing tumor cells have shown that VEGF gene expression increased in confluent slow growing H460 cells compared with sparse fast growing cells (32). These results indicate that partial inhibition of one cell factor activates the expression of other cell factors. Further work is being pursued. 


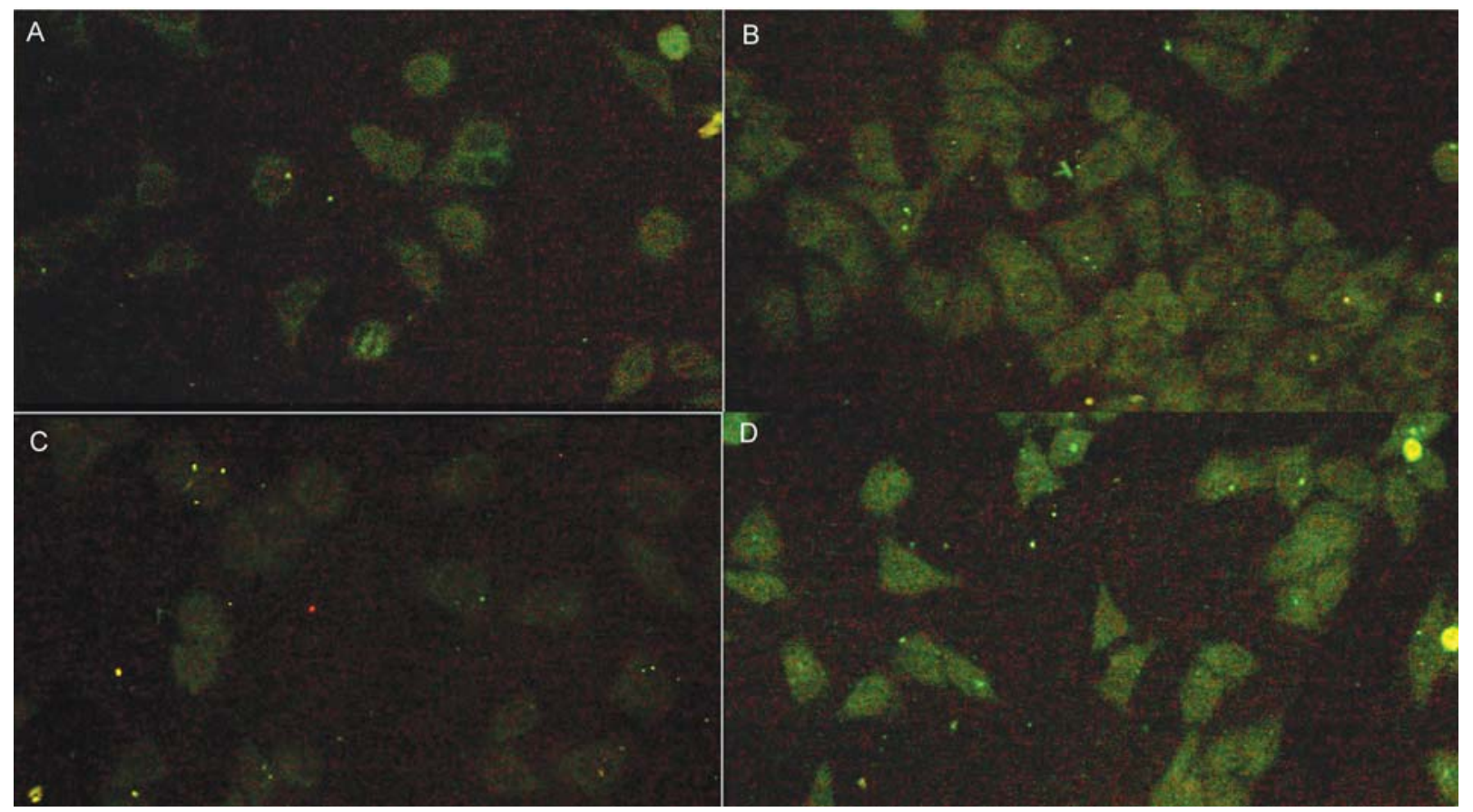

Figure 8. Immunofluorescence staining of angiogenin in bFGF transfected cells and control cells. HeLa cells (A) and vector-transfected cells (B) show a moderate amount of immunoreactivity for angiogenin; bFGF sense transfected cells (C) have low levels of angiogenin immunoreactivity; bFGF antisense transfected cells (D) demonstrate high levels of angiogenin immunoreactivity.

Moreover, Fig. 9 shows that in the bFGF antisense transfectants and the control cells, the exogenous angiogenininduced cell proliferation was increased to the level of the bFGF sense transfectants. However, the exogenous angiogenin-induced cell proliferation had no change in the bFGF sense transfectants. A possible explanation for this is angiogenin could promote cell proliferation. Tsuji et al have demonstrated that angiogenin could promote HeLa cell proliferation by regulating rRNA transcription and ribosome biogenesis (14). The bFGF sense transfected cells need more nutrients from the culture medium or from intracellular stores, such as other growth factors, second messengers, or metabolites, resulting from over stimulation of a pathway through which the growth-promoting effects of bFGF are mediated. In bFGF sense transfectants, cell proliferation is not increased with exogenous angiogenin because there are not enough nutrients to supply for cell proliferation. As cell proliferation in the control cells and bFGF antisense transfected cells were increased in the same conditions, their slower metabolic rate might have permitted them to maintain adequate stores of all necessary nutrients. Obviously, both bFGF and angiogenin could stimulate HeLa cell growth. How do angiogenin and bFGF coordinate to stimulate HeLa cell growth? This would be worth examining.

Many angiogenic factors secreted by HeLa cells have been investigated, and it was demonstrated that they contribute to the process of HeLa cell growth. The interrelationships among these factors, however, are still unclear. Our results showed that both bFGF and angiogenin could stimulate HeLa cell growth. Furthermore, endogenous bFGF negatively affects the expression of angiogenin in HeLa cells. These findings suggest that inhibition of bFGF alone is not a promising strategy to inhibit angiogenesis. Further work

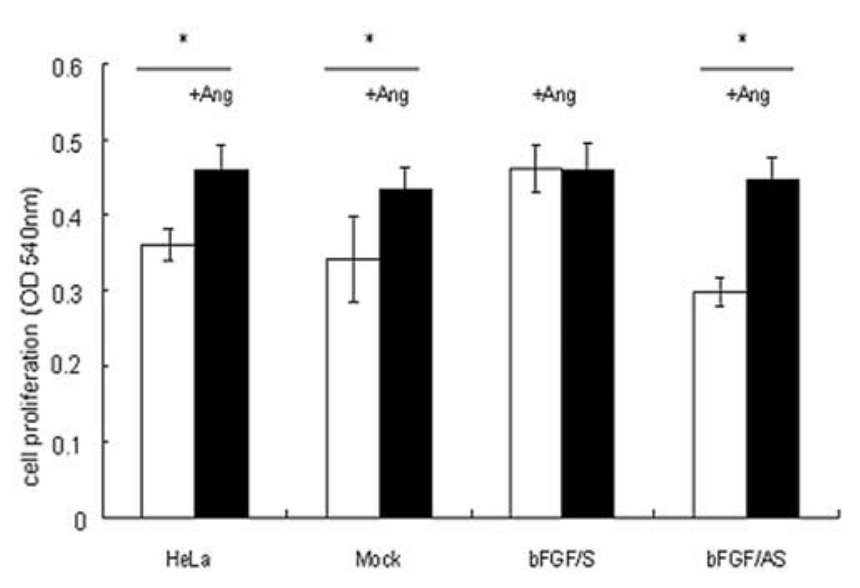

Figure 9. Influence of exogenous angiogenin on cell proliferation in bFGF transfectants and control cells. Cells $\left(7.0 \times 10^{3}\right)$ were seeded into a 96-well plate and cultured in serum-free medium. Angiogenin $(1 \mathrm{mg} / \mathrm{ml})$ was added to the cells immediately after the cells were seeded. After $48 \mathrm{~h}$ of incubation at $37^{\circ} \mathrm{C}$, MTT assay was performed and the optical density (OD) value at $540 \mathrm{~nm}$ was recorded. Data shown are means \pm SD of 4 independent experiments $\left({ }^{*} \mathrm{P}<0.05\right)$.

needs to be carried out in order to understand the role of angiogenic factors in HeLa cells and to find an effective treatment for cervical cancer.

\section{Acknowledgements}

We thank Dr Guo-fu Hu (Harvard Medical School) for kindly providing experimental materials and help during the experimental process. This study was supported by the Development and Reform Commission of Jilin province, Grant 2007-1033. 


\section{References}

1. zur Hausen H: Papillomaviruses and cancer: from basic studies to clinical application. Nat Rev Cancer 2: 342-350, 2002.

2. Ozalp S, Yalcin OT, Oner U, Tanir HM, Ackalin M and Sarac I: Microvessel density as a prognostic factor in preinvasive and invasive cervical lesions. Eur J Gynaecol Oncol 24: 425-428, 2003.

3. Fett JW, Strydom DJ, Lobb RR, Alderman EM, Bethune JL, Riordan JF and Vallee BL: Isolation and characterization of angiogenin, an angiogenic protein from human carcinoma cells. Biochemistry 24: 5480-5486, 1985.

4. Olson KA, Byers HR, Key ME and Fett JW: Prevention of human prostate tumor metastasis in athymic mice by antisense targeting of human angiogenin. Clin Cancer Res 7: 3598-3605, 2001.

5. Montero S, Guzman C, Cortes-Funes H and Colomer R: Angiogenin expression and prognosis in primary breast carcinoma. Clin Cancer Res 4: 2161-2168, 1998.

6. Chopra V, Dinh TV and Hannigan EV: Circulating serum levels of cytokines and angiogenic factors in patients with cervical cancer. Cancer Invest 16: 152-159, 1998.

7. Li D, Bell J, Brown A and Berry CL: The observation of angiogenin and basic fibroblast growth factor gene expression in human colonic adenocarcinomas, gastric adenocarcinomas, and hepatocellular carcinomas. J Pathol 172: 171-175, 1994.

8. Shimoyama S, Shimizu N, Tsuji E, Yamasaki K, Kawahara M and Kaminishi M: Distribution of angiogenin and its gene message in colorectal cancer patients and their clinical relevance. Anticancer Res 22: 1045-1052, 2002.

9. Chopra V, Dinh TV and Hannigan EV: Serum levels of interleukins, growth factors and angiogenin in patients with endometrial cancer. J Cancer Res Clin Oncol 123: 167-172, 1997.

10. Shimoyama $\mathrm{S}$ and Kaminishi $\mathrm{M}$ : Increased angiogenin expression in gastric cancer correlated with cancer progression. J Cancer Res Clin Oncol 126: 468-474, 2000.

11. Moroianu J and Riordan JF: Nuclear translocation of angiogenin in proliferating endothelial cells is essential to its angiogenic activity. Proc Natl Acad Sci USA 91: 1677-1681, 1994.

12. Xu ZP, Tsuji T, Riordan JF and Hu GF: The nuclear function of angiogenin in endothelial cells is related to rRNA production. Biochem Biophys Res Commun 294: 287-292, 2002.

13. Xu ZP, Tsuji T, Riordan JF and Hu GF: Identification and characterization of an angiogenin-binding DNA sequence that stimulates luciferase reporter gene expression. Biochemistry 42 : $121-128,2003$

14. Tsuji T, Sun Y, Kishimoto K, Olson KA, Liu S, Hirukawa S and Hu GF: Angiogenin is translocated to the nucleus of HeLa cells and is involved in ribosomal RNA transcription and cell proliferation. Cancer Res 65: 1352-1360, 2005.

15. Basilico C and Moscatelli D: The FGF family of growth factors and oncogenes. Adv Cancer Res 59: 115-165, 1992

16. Montesano R, Vassalli JD, Baird A, Guillemin R and Orci L: Basic fibroblast growth factor induces angiogenesis in vitro. Proc Natl Acad Sci USA 83: 7297-7301, 1986.

17. Fenig E, Wieder R, Paglin S, Wang H, Persaud R, HaimovitzFriedman A, Fuks Z and Yahalom J: Basic fibroblast growth factor confers growth inhibition and mitogen-activated protein kinase activation in human breast cancer cells. Clin Cancer Res 3: $135-142,1997$.
18. Gross JL, Herblin WF, Dusak BA, Czerniak P, Diamond MD Sun T, Eidsvoog K, Dexter DL and Yayon A: Effects of modulation of basic fibroblast growth factor on tumor growth in vivo. J Natl Cancer Inst 85: 121-131, 1993.

19. Iwasaki A, Kuwahara M, Yoshinaga Y and Shirakusa T: Basic fibroblast growth factor (bFGF) and vascular endothelial growth factor (VEGF) levels, as prognostic indicators in NSCLC. Eur J Cardiothorac Surg 25: 443-448, 2004.

20. Ogasawara S, Yano H, Higaki K, Takayama A, Akiba J, Shiota K and Kojiro M: Expression of angiogenic factors, basic fibroblast growth factor and vascular endothelial growth factor, in human biliary tract carcinoma cell lines. Hepatol Res 20: 97-113, 2001

21. Alba E, Llombart A, Ribelles N, Ramos M, Fernández R, Mayordomo JI, Tusquets I, Gil M, Barnadas A, Carabante F, Ruiz M, Vera R, Palomero I, Soriano V, González J and Colomer R: Serum endostatin and bFGF as predictive factors in advanced breast cancer patients treated with letrozole. Clin Transl Oncol 8: 193-199, 2006.

22. Gravdal K, Halvorsen OJ, Haukaas SA and Akslen LA: Expression of bFGF/FGFR-1 and vascular proliferation related to clinicopathologic features and tumor progress in localized prostate cancer. Virchows Arch 448: 68-74, 2006.

23. Sliutz G, Tempfer C, Obermair A, Reinthaller A, Gitsch G and Kainz C: Serum evaluation of basic fibroblast growth factor in cervical cancer patients. Cancer Lett 94: 227-231, 1995.

24. Kishimoto K, Liu S, Tsuji T, Olson KA and Hu GF: Endogenous angiogenin in endothelial cells is a general requirement for cell proliferation and angiogenesis. Oncogene 4: 445-456, 2005.

25. Song J, Wang J, Yang J, Jiang C, Shen W and Wang L: Influence of angiogenin on the growth of A375 human melanoma cells and the expression of basic fibroblast growth factor. Melanoma Res 6: 119-126, 2006.

26. Ramírez-Solis R, Rivera-Pérez J, Wallace JD, Wims M, Zheng H and Bradley A: Genomic DNA microextraction: a method to screen numerous samples. Anal Biochem 201: 331-335, 1992.

27. Heydarkhan-Hagvall S, Helenius G, Johansson BR, Li JY, Mattsson E and Risberg B: Co-culture of endothelial cells and smooth muscle cells affects gene expression of angiogenic factors. J Cell Biochem 89: 1250-1259, 2003.

28. Kuhn H, Köff C, Konrad J, Riedel A, Gessner C and Wirtz H: Influence of basic fibroblast growth factor on the proliferation of non-small cell lung cancer cell lines. Lung Cancer 44: 167-174, 2004.

29. Kuhn H, Konrad J, Holtz S, Salameh A, Gessner C, Hammerschmidt $\mathrm{S}$ and Wirtz $\mathrm{H}$ : Enhanced expression of VEGF following bFGF inhibition in non-small cell lung cancer cell lines. Lung Cancer 54: 149-153, 2006.

30. Polytarchou C, Gligoris T, Kardamakis D, Kotsaki E and Papadimitriou E: X-rays affect the expression of genes involved in angiogenesis. Anticancer Res 24: 2941-2945, 2004.

31. Fersis N, Smyczek-Gargya B, Armeanu S, Gagulic E, Pantic L, Relakis K, Friedrich M and Wallwiener D: Changes in vascular enothelial growth factor (VEGF) after chemoendocrine therapy in breast cancer. Eur J Gynaecol Oncol 25: 45-50, 2004.

32. Kuhn H, Bräunlich J, Hammerschmidt $\mathrm{S}$ and Wirtz H: Candidate genes upregulated in density dependent growth inhibition of lung cancer cells. Int J Oncol 25: 1481-1487, 2004. 